\title{
Paper-based web connected objects and the Internet of Things through EKKO
}

\author{
John Mills, Paul Egglestone, Mark Lochrie, Martin Skelly ${ }^{1}$ \\ Media Innovation Studio \\ University of Central Lancashire \\ Preston, PR1 2HE \\ \{ jmills; pegglestone; mlochrie \}@uclan.ac.uk \\ ${ }^{1}$ Uniform \\ Third Floor, Link 19 \\ 9-10 Bold Street, Liverpool, L1 4DN \\ Martin.skelly@uniform.net
}

\begin{abstract}
Paper has existed as a communications 'platform' for thousands of years. It's 'versioning history' spans papyrus, parchment and pulp, and when paper became a scalable and mass-production item, most famously via the Guttenberg press, it sparked unparalleled social and political change. It's a technology that's had 'impact'. More recently, News and Information - a sector with paper at its core - has seen substantial editorial and commercial disruption from digital communications networks. This paper outlines a collaborative project between journalism, media and technology researchers, and commercial product designers, exploring the potential of paper-based web-connected objects. Our work examines how emergent conductive ink technologies could offer a disruptive alternative to existing media products, and explores how to create, power and populate a connected paper platform, and analyse user activity. Through a range of industry partnerships with newspaper, magazine and book publishers, our research creates new paper affordances and interactions, and positions paper as a digital disruptor.
\end{abstract}

\section{Categories and Subject Descriptors}

Hardware $\sim$ Hardware-software codesign

\section{Keywords}

Paper. Interactive; Media; Conductives; Printed Electronics; Internet of Things

\section{INTRODUCTION}

Over the last decade, the news and media has faced unprecedented disruption that has spanned commercial revenue streams, audience trust and an increasingly complex and nuanced information marketplace [3, 4], with connected devices and robust digital infrastructures creating a media environment that is populated by millions of connected citizens, and is no longer the sole realm of dominant mainstream media [1]. Within this rapidly evolving multimedia landscape, paper has remained static. Its core affordances remain constant, and unconnected.

Permission to make digital or hard copies of part or all of this work for personal or classroom use is granted without fee provided that copies are not made or distributed for profit or commercial advantage and that copies bear this notice and the full citation on the first page. Copyrights for third-party components of this work must be honored. For all other uses, contact the Owner/Author.

Copyright is held by the owner/author(s).

British HCI 2015, July 13-17, 2015, Lincoln, United Kingdom

ACM 978-1-4503-3643-7/15/07.

http://dx.doi.org/10.1145/2783446.2783610

\section{BACKGROUND}

Interactive paper, initially produced by commercial organisation Novalia and further developed in collaboration with academic partners within the EPSRC-funded Interactive Newsprint project 1 , is a type of "smart" paper created by printing electrical devices on various substrates. Printing typically uses common printing equipment or other low-cost equipment suitable for defining patterns on material, such as screen printing, flexography, gravure, offset lithography and inkjet. The resultant paper matter is responsive to a human touch, can connect to the internet and play a sound once a certain area on the surface is pressed via an embedded speaker or via a locally connected set of Bluetooth or radio frequency headphones. This means that sheets of paper can turn into reactive displays. This technology provides an alternative to the range of existing alternatives such as flexible e-ink displays, graphene and OLEDs (Organic LightEmitting Diodes) - which represent a market sector which is expected to expand rapidly over the short to medium term. During this project, which ran between 2011 and 2013, a number of the research teams, in collaboration with a range of commercial partners spanning experts in conductive ink printings, design implementation and news and information publishers, began to create a range of experience prototypes designed to test use-cases for print capable of capacitive touch, and audio responses.

In this paper, our research explores alternative printed electronics and conductive inks, new use-cases, service technologies, and interactions with web-connected paper. There can be no mistaking the impact the maker community has had on developing low cost electronic solutions aimed at the Do It Yourself (DIY) audiences [2] amongst others are a good example of this.

This research has been undertaken with industry partners including newspapers, magazines and book publishers. The authors are exploring open source, free systems and hardware capable of attaching and transferring data to and from a printed object. Following on from Interactive Newsprint, our current rapid prototypes navigate new perspectives, technologies, and resulting interactions around how publishers and readers could utilise web-connected paper powered by a 'connected clip' dubbed EKKO. Our research implements Arduino and Electric Imp combinations, particularly when deployed against dynamic printed audio content from regional newspapers - the Liverpool Echo, national magazines - Stuff and national book publishers.

\footnotetext{
${ }^{1}$ http://interactivenewsprint.org
} 


\section{EKKO: 'THE PAPER CLIP' PROTOTYPE}

Over the last year, design research was conducted around an Internet-connected paperweight that pushed analytics data, and played audio stored locally on the object. During initial alpha and beta testing, it became apparent the User Experience (UX) was problematic. Once placed on the paper, it was easily knocked out of registration and its footprint, due to internal components, was bulky. As such, it also demanded a lot of real estate on the print. Further research was conducted which led to conceptualising the object as a bookmark or paperclip, whereby it hangs off the edge of the print. To decrease its size and chunkiness of the object, the audio player component was replaced with a mobile device. The pairing of the two devices is required before the user can expeiernce the print. This is currently achived by entering the name of EKKO (typically a user friendly name or MAC Address) into the mobile application. The user then selected the publication they wish to interact with and in turn the server logs the users device ID as active and sets their publication.

The linking of objects to the Internet and the utilisation of the ubiquitous mobile device for playback opens up thousands of possible interactions and content types. The current working prototype - named EKKO - clips over the edge of a piece of print (Fig. 1), and applies pressure to the conductive ink to ensure a good connection. It has been prototyped with an Electric Imp ${ }^{2}$ combined with a capacitance sensor to measure the ink button presses, a small rechargeable Li-Po battery and an LED for user feedback. Once a sensor is pressed, the object posts the sensor value to the webserver, which in turn pushes the content for playback to the mobile device. The server uses Pusher's real time API $^{3}$ to manage connections and push content to addressed mobile devices.

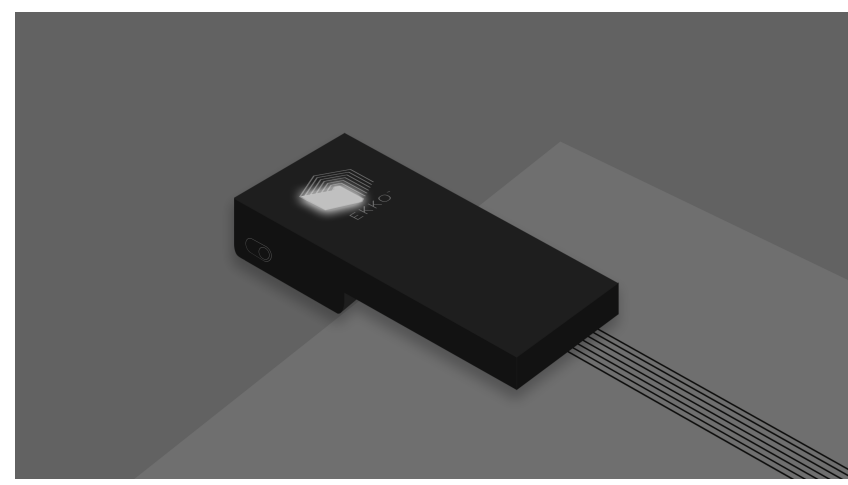

Figure 1. mock up of an EKKO connected to print

\section{AN EKKO EXPERIENCE}

Going forward with the research partners, each prototype demonstrates how EKKO can be used in varying scenarios. The first prototype was to utilise the mobile's audio capabilities. The next is to utilise the screen and use the print as a games controller to create a simple button game. Other concepts were to explore the use of extending the story through audio/video narratives: by pressing the illustration on the print and you

\footnotetext{
2 electricimp.com

${ }^{3}$ Pusher.com
}

hear/see insights into how it was conceived, or the purpose of the character within the story. Other simplified solutions are to use the print as a media controller to play, pause, stop video and audio content. Furthermore the possibilities of creating new interactions by combining the use of EKKO with other forms of print such as artwork, boardgames, posters, restaurant menus etc are all possible applications for connecting print to the Internet.

\section{CONCLUSIONS \& FUTURE WORK}

Beyond the confines of this rapid prototyping, the research team intends to develop a range of digital tools to lay the foundation of the mass scaling of EKKO and relating technologies. A key element of this is creation of a content management system and accompanying analytics platform that would allow publishers and other users to populate printed objects and monitor a range of interactions. This could be a substantial development as, for the first time, paper will be able to provide user data to publishers. Research would also be beneficial beyond the confines of news and information, and to examine how conductive inks and the placement of connected paper within IoT could offer a range advantages to users across different scenarios.

There are a number of challenges to future development. Some are technical, specifically relating to the platform; delivery of smaller and faster microchips with the capacity to support a greater number of more complex interactions with product would improve the user experience and enrich the data capabilities. Some are bigger HCI questions for the design of the new platform; creating interactions may need a graphical lexicon to visually describe how to turn digital paper on, control the audio levels or scroll through the audio. Some challenges are editorial and relate to how the technology might change narrative structure and the way a listener or reader receives the story, and how, using the aforementioned content management system and accompanying analytics platform, the analysis and presentation of 'paper data' could be refined to enable publishers and advertisers of all shapes and sizes to extract information.

\section{ACKNOWLEDGEMENTS}

The research team would like to thank our partners for their time, creative input and content. These include Paul Gallagher at Trinity Mirror, Will Findlater and Will Dunn at Haymarket Media, Tom Metcalfe at Tom Metcalfe Studios and Professor Jon Rogers at the University of Dundee.

\section{REFERENCES}

[1] Deuze, M., Bruns, A., Neuberger, C., (2007), Preparing for an age of participatory news, Journalism Practice, volume 1 , issue 3 , pp322-328

[2] Dittrich. Y., Burnett. M., Morch., Redmiles. D., (2013), End-User Development: 4th International Symposium, ISEUD 2013, Copenhagen

[3] Meyer, P., (2009), The Vanishing Newspaper: saving journalism in the information age, Univerity of Missouri, Columbia

[4] Pew Research Centre, The Losses Legacy, http://www.journalism.org/2014/03/26/the-losses-legacy, accessed 1 May 2014 